\title{
NSF told to ease up cost-share demands
}

[WASHINGTON] Programme officers at the US National Science Foundation (NSF) have been told to stop using their considerable clout with principal investigators to negotiate down the size of research grants. This tactic shifts part of the cost of the research from the NSF to the university receiving the grant.

Last week, the National Science Board, the NSF's governing body, approved a new cost-sharing policy that prohibits the reduction of a grant without a corresponding reduction in the scope of the proposed work. It also requires cost sharing to be declared up-front, and prohibits its use as an unwritten criterion for selecting grants.

"There is a lively interest among members of the community and the board with regard to cost sharing," says John Armstrong of IBM, a member of the board. "We'll be taking a substantial step forward with this policy."

University administrators and researchers have been growing alarmed about the practice - which they regard as 'cost shifting' from the government to the universities - because of its cost and the tension it creates between grant recipients and administrators.

Administrators blame investigators for surrendering money to the government in unauthorized negotiations with the officials who administer the grants. Researchers may increase their chances of winning a grant if they can reduce their claim, because the programme managers have limited sums of money to support particular fields.

Officials admit that the issue has been around for years. But they say it has only emerged as a major bone of contention as government auditors have begun to unearth some of the dark secrets of university finance, prompted by concern in the Congress.

Every few years, auditors descend on every research university to check the amount spent directly on research, and that spent indirectly to support research. The ratio between the two - the overhead rate - critically determines how much money the government should pay to the institution to cover the costs of commissioned research.

The auditors insist that the time spent by investigators on research projects should be treated as a direct cost, even if the investigators have not claimed the full amount from the funding agency that supports them. If, for example, a principal investigator agrees to take no money from the NSF to cover time spent on a project, but subsequently spends half of his or her time on it, the auditors will insist that the time was spent on research.

If such a practice is repeated across dozens of grants, it increases the university's direct research costs, and therefore reduces the overhead rate it can claim. One institution in Massachusetts recently repaid \$12 million to the government after an audit, and another in New York paid back \$6 million.

Two weeks ago, President Bill Clinton promised to make arrangements for cost sharing more transparent across the government, as part of a new partnership with the universities (see Nature 399, 3; 1999). The agency most widely accused of shifting costs to the universities is the NSF, the largest supporter of non-biomedical research at US universities. (Grants from the National Institutes of Health usually cover researchers' salaries, so disputes about cost sharing are less likely.)

"The NSF stands out because its programme managers are known to push hard to get universities to pay for a larger share of research costs," says Milton Goldberg of the Council on Government Relations, which represents universities in Washington.

The issue has dominated recent regional meetings at which researchers and university administrators met NSF officials to discuss grievances. "It is like a powder keg going off" when cost sharing is raised, says one official.

The new policy is intended to quell this discontent and address concerns elsewhere in the government that NSF cost-sharing practice is driving down overhead rates to levels that do not reflect the full cost of research. A White House official points out that artificially low overhead rates will save money in the short term, but will damage research in the long term by deterring universities from investing in equipment and buildings.

The policy states that any cost-sharing requirement in an NSF programme will be "clearly stated in the programme announcement", and that negotiations on cost sharing will be decoupled from the merit review process that determines who receives grants.

Standard NSF grants should require no cost sharing beyond an arcane statutory requirement for institutions to bear one per cent of project costs, says the policy statement. It adds that programme managers "may not negotiate or impose cost sharing or

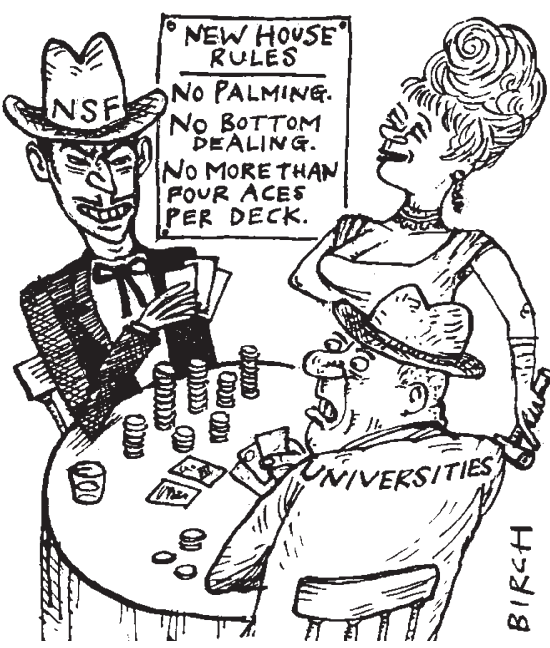

other institutional commitments" during the final discussions they hold with principal investigators to determine grant amounts.

In these final negotiations, the statement concludes, "any reduction of ten per cent or more from the amount proposed should be accompanied by a corresponding reduction in the scope of the project, unless the program officer, principal investigator and institution clearly agree" that the cut can be made without the institution incurring extra costs.

But Mary Clutter, NSF associate director for life sciences, one of the officials whose staff stand accused of squeezing investigators during grant negotiations, doubts that the policy will make much difference to the administration of ordinary NSF grants. "They're not supposed to be doing these negotiations even now, so I don't know if [the policy] will have that much impact," she says. But she says she likes the policy because it will make it clear what cost sharing is expected.

Response in Washington was sceptical. "It is likely to make a small difference," says Goldberg. "Success is problematic because program officers are pretty good, and there are ways of getting round it." Colin Macilwain

\section{Future of Spectrum X mission still cloudy}

[MUNICH] Representatives of national space agencies involved in the Spectrum $\mathrm{X}$ collaboration, an ambitious and longdelayed X-ray astronomy mission, will meet in Moscow next week to discuss prospects for the project, now due for launch in 2001.

Space agencies have already built instruments for the mission, which was conceived by the former Soviet Academy of Sciences, for a mid-1990s launch.

But the building of the main spacecraft, by Russia's satellite manufacturer Lavochkin Association, has never been completed. The problem is believed to be financial.

"Space agencies have been frustrated by unclear pictures of what is happening," says Paul Merdin of the British National Space Centre. Britain has paid $\mathfrak{E} 13$ million (US\$21 million) towards the cost of JET-X (Joint European Telescope). But, like other Spectrum $\mathrm{X}$ instruments, JET-X has been sitting in storage for several years.

Scientists hope the Moscow meeting will restore confidence that the new launch date of 2001 will be met. Further delays, they fear, may render Spectrum X's scientific capabilities outdated, given that three major $\mathrm{X}$-ray astronomy missions are to be launched by Europe, the United States and Japan in the coming months. Alison Abbott 